\title{
Migrant workers in China need emergency psychological interventions during the COVID-19 outbreak
}

Zi-Han Liu ${ }^{1,2,3^{*}}$ D, Yan-Jie Zhao ${ }^{1,2,3 \dagger}$, Yuan Feng ${ }^{4 \dagger}$, Qinge Zhang ${ }^{4 \dagger}$, Bao-Liang Zhong ${ }^{5 \dagger}$, Teris Cheung ${ }^{6}$, Brian J. Hall ${ }^{7}$ and Yu-Tao Xiang ${ }^{1,2,3+}$

\begin{abstract}
The 2019 novel coronavirus disease (COVID-19) has been found in more than 200 countries worldwide since December, 2019. In China, a major reason for the rapid transmission of the COVID-19 in early stage of the outbreak is the huge numbers of passengers boarding their "last train home" to meet family members during the Spring Festival. Most of these travelers were internal migrant workers. In order to reduce the risk of the COVID-19 transmission, public transportation networks were suspended, and many migrant workers who returned to their hometowns needed to be quarantined for 2 weeks, which led to the delay of returning back to cities to work. Many businesses have temporarily closed because of the risk of COVID-19 transmission, leading to unemployment of many workers. Sudden loss of income and further quarantine enforcement in cities can exacerbate existing mental health problems or trigger new mental disorders among affected migrant workers. However, to date no specific guidelines or strategies about mental health services of migrant workers have been released. Health authorities and professionals should pay more attention to this vulnerable group and provide timely mental health service support for those in need.
\end{abstract}

Keywords: COVID-19, Migrant workers, Mental health, China

\section{Background}

Since the 2019 novel coronavirus disease (COVID-19) was first reported in Wuhan, Hubei province, China at the end of 2019, it has been found in more than 200 countries, and gained enormous attention worldwide. In China, a major reason for the rapid transmission of the COVID-19 in early stage of the outbreak is the huge numbers of passengers boarding their "last train home"

\footnotetext{
* Correspondence: t1521981446@126.com

${ }^{\dagger}$ Zi-Han Liu, Yan-Jie Zhao, Yuan Feng, Qinge Zhang, Bao-Liang Zhong and

Yu-Tao Xiang contributed equally to this work.

'Unit of Psychiatry, Institute of Translational Medicine, Faculty of Health

Sciences, University of Macau, 3/F, Building E12, Avenida da Universidade,

Taipa, Macau SAR, China

${ }^{2}$ Center for Cognition and Brain Sciences, University of Macau, Macao SAR, China

Full list of author information is available at the end of the article
}

to meet family members during the Spring Festival in China. This is usually the peak season for Chinese citizens to travel to and from their hometowns. There were more than 1.14 billion trips between January 10 and January 24, 2020. Most travelers were, in fact, internal migrant workers (migrant workers hereafter) [3]. Due to mass quarantine measures and loss of income, mental health problems are common among Chinese migrant workers. A comprehensive introduction to mental health problems and related issues among migrant workers in China is warranted.

\section{Main text}

Migrant workers refer to individuals aged 16 years and older, who leave their original residence in rural areas and work in cities for 3 months or more. Migrant workers 
account for around $1 / 5$ of the whole Chinese population (approximately 300 million) [8]. On the one hand, migrant workers bring about abundant cheap labor to the cities and speed up economic growth. On the other hand, they are part of the low socio-economic population in cities. Migrant workers can only take up temporary jobs in cities because their legal residence ('hukou') is still in their hometown rural areas, rather than in the cities where they live and work. In China the "hukou" system is closely linked with an individual's access to accommodation, education, social welfare, and health care. Without a "hukou", migrant workers cannot be fully covered by health insurance in cities where they temporarily work. Compared to permanent residents in cities (i.e., those with 'Hukou' in cities), most migrant workers in China have insufficient financial savings, low education levels, a high level of life stress, limited time and money to see doctors or even being discriminated by others, which contributes to a higher prevalence of mental health problems than observed in the general population [10]. This claim was evidenced by a recent study which reported that the prevalence of depression was $20.1 \%$ in Chinese migrant workers [14], which was almost four times (5.9\%) higher than those rural residents in China [19].

In order to reduce the risk of the COVID-19 transmission and facilitate early identification, and isolation of confirmed and suspected cases, mass quarantine was widely adopted and public transportation was suspended in many areas of China. Due to fear of infection, uncertainty of the COVID-transmission, and misinformation about the disease in social media, mental health problems, such as sleep disturbances, depression and anxiety, are common in the general public and migrant workers $[4,7,13,15,17]$. In addition, during the COVID-19 outbreak many migrant workers who returned to hometowns needed to be quarantined for 2 weeks. These migrants thus had to postpone their journey back to cities to work. Although roughly 1 million migrant workers were able to return to cities $[16,18]$, due to the potential risk of COVID-19 transmission, many businesses temporarily closed leading to unemployment. Sudden loss of income has affected their ability to support their families, and they have experienced increased discrimination, which could further exacerbate existing or trigger new mental health problems, such as boredom, anger, anxiety, and guilt, in migrant workers. However, regular mental health education is typically not available for this population during the COVID-19 outbreak, and financial hardship, further quarantine measures and stigma associated with mental illness [12] are key barriers deterring them from seeking timely mental health treatments if needed. Moreover, basic health insurance for migrant workers in many cities of China do not completely cover mental health services; furthermore, private health insurance is not affordable for migrant worker. These factors make migrant workers less likely to seek help from mental health services when needed.

In the past several months, a number of guidelines on emergency psychological interventions have been developed in China [5]. For example, the National Health Commission of China (NHC) has integrated psychological crisis intervention into general disease prevention. Major mental health associations and academic societies in China also have developed guidelines and expert consensus for mental health institutions, such as the 'The Manual of Mental Health Services during of the COVID outbreak'. Following these guidelines, some crisis psychological services, such as 24-h hotlines and online mental health education, have been set up in many areas of China [6]. However, lack of knowledge of mental health, low education level, perceived stigma and limited access to online information make it hard for migrant workers to benefit from these services. The mental health services needs of certain special populations including older adults, children and adolescents, pregnant women, and health professionals, have been addressed in recent guidelines, such as the 'Psychological Adjustment Guidelines for Coping with the New Coronavirus Pneumonia' [4]. In contrast, however, the mental health of migrant workers was neglected. To the best of our knowledge, no specific guidelines on mental health of migrant workers have been released in China during COVID19 outbreak.

Based on the currently available health resources and experiences of previous bio-disasters, several measures may be helpful to improve mental health services for migrant workers during the COVID-19 outbreak. First, relevant guidelines and/or expert consensus on mental health of migrant workers should be developed. Second, regular mental health screening should be performed for this population, such as using online self-report instruments that have recently been widely used $[1,2,11]$. Third, free and accessible mental health services, such as online psychological counseling, hotline services and other telehealth services, should be established for migrant workers. In addition, free online education on mental health is useful to improve their awareness of mental health and help them seek help from mental health services [4]. Finally, based on the experiences obtained during the Middle East Respiratory Syndrome (MERS) epidemic in Korea [9], social workers and other professionals can play an important role in providing social support and relevant education for migrant workers who are in need during the COVID-19 outbreak. 


\section{Conclusion}

Migrant workers are a vulnerable group in China during the COVID-19 outbreak. Both health authorities and health professionals should pay more attention to this population and provide a timely mental health services for those in need.

\section{Abbreviation \\ COVID-19: The 2019 novel coronavirus disease}

\section{Acknowledgements}

None.

\section{Authors' contributions}

Yu-Tao Xiang conceived the idea. Zi-Han Liu wrote the manuscript with information provided by Yan-Jie Zhao. Yuan Feng, Qinge Zhang, Bao-Liang Zhong, Teris Cheung and Brian J. Hall, PhD revised the manuscript. The author(s) read and approved the final manuscript.

\section{Funding}

The study was supported by the National Science and Technology Major Project for investigational new drug (2018ZX09201-014), the Beijing Municipal Science \& Technology Commission (No. Z181100001518005), and the University of Macau (MYRG2019-00066-FHS).

\section{Availability of data and materials}

Not applicable for this study.

\section{Ethics approval and consent to participate}

Not applicable for this study.

\section{Consent for publication}

Not applicable for this study.

\section{Competing interests}

Authors declare no competing interest.

\section{Author details}

${ }^{1}$ Unit of Psychiatry, Institute of Translational Medicine, Faculty of Health Sciences, University of Macau, 3/F, Building E12, Avenida da Universidade, Taipa, Macau SAR, China. ${ }^{2}$ Center for Cognition and Brain Sciences, University of Macau, Macao SAR, China. ${ }^{3}$ Institute of Advanced Studies in Humanities and Social Sciences, University of Macau, Macao SAR, China. ${ }^{4}$ The National Clinical Research Center for Mental Disorders \& Beijing Key Laboratory of Mental Disorders, Beijing Anding Hospital \& the Advanced Innovation Center for Human Brain Protection, Capital Medical University, Beijing, China. ${ }^{5}$ Affiliated Wuhan Mental Health Center, Tongji Medical College of Huazhong University of Science \& Technology, Wuhan, Hubei Province, China. ${ }^{6}$ School of Nursing, Hong Kong Polytechnic University, Hong Kong SAR, China. 7 Department of Health, Behavior and Society, Johns Hopkins Bloomberg School of Public Health, Baltimore, MD, USA.

Received: 15 May 2020 Accepted: 10 August 2020

Published online: 19 August 2020

\section{References}

1. Dobie DJ, Kivlahan DR, Maynard C, Bush KR, McFall M, Epler AJ, Bradley KA Screening for post-traumatic stress disorder in female Veteran's Affairs patients: validation of the PTSD checklist. Gen Hosp Psychiatry. 2002;24(6): 367-74. https://doi.org/10.1016/s0163-8343(02)00207-4.

2. Leung DYP, Mak YW, Leung SF, Chiang VCL, Loke AY. Measurement invariances of the PHQ-9 across gender and age groups in Chinese adolescents. Asia Pac Psychiatry. 2020:e12381. https://doi.org/10.1111/appy 12381.

3. Li L. 2020. No return travel peak expected as holiday to end soon. In (2020 2.15 ed.). chinadaily.com.cn. Beijing: China Daily.

4. Li W, Yang Y, Liu ZH, Zhao YJ, Zhang Q, Zhang L, Xiang YT. Progression of mental health services during the COVID-19 outbreak in China. Int J Biol Sci. 2020;16(10):1732-8. https://doi.org/10.7150/ijbs.45120.
5. Li X, Yang H, Wang H, Liu X. Effect of health education on healthcareseeking behavior of migrant Workers in China. Int J Environ Res Public Health. 2020;17(7). https://doi.org/10.3390/ijerph17072344.

6. Li Z, Ge J, Yang M, Feng J, Qiao M, Jiang $R$, et al. Vicarious traumatization in the general public, members, and non-members of medical teams aiding in COVID-19 control. Brain Behav Immun. 2020. https://doi.org/10.1016/j.bbi. 2020.03.007.

7. Liem A, Wang C, Wariyanti Y, Latkin CA, Hall BJ. The neglected health of international migrant workers in the COVID-19 epidemic. Lancet Psychiatry. 2020;7(4):e20. https://doi.org/10.1016/s2215-0366(20)30076-6.

8. National Bureau of Statistics. (2019). Report on the monitoring and investigation of migrant workers in 2018 (in Chinese). Retrieved from http:// www.stats.gov.cn/tjsj/zxfb/201904/t20190429 21662268.html.

9. Park HJ, Lee BJ. The role of social work for foreign residents in an epidemic: the MERS crisis in the Republic of Korea. Soc Work Public Health. 2016:31(7): 656-64. https://doi.org/10.1080/19371918.2016.1160352.

10. Ren F, Yu X, Dang W, Niu W, Zhou T, Lin Y, Yuan P. Depressive symptoms in Chinese assembly-line migrant workers: a case study in the shoe-making industry. Asia Pac Psychiatry. 2019;11(2):e12332. https://doi.org/10.1111/ appy.12332.

11. Spitzer RL, Kroenke K, Williams JB, Löwe B. A brief measure for assessing generalized anxiety disorder: the GAD-7. Arch Intern Med. 2006;166(10): 1092-7. https://doi.org/10.1001/archinte.166.10.1092.

12. Shi W, Shen Z, Wang S, Hall BJ. Barriers to professional mental health helpseeking among Chinese adults: a systematic review. Front Psychiatry. 2020; 11:442. https://doi.org/10.3389/fpsyt.2020.00442

13. Wang C, Pan R, Wan X, Tan Y, Xu L, Ho CS, Ho RC. Immediate psychological responses and associated factors during the initial stage of the 2019 coronavirus disease (COVID-19) epidemic among the general population in China. Int J Environ Res Public Health. 2020;17(5). https://doi.org/10.3390/ ijerph17051729.

14. Wang L, Chen H, Ye B, Gao J, Dai J, Wang F, Fu H. Mental health and selfrated health status of internal migrant workers and the correlated factors analysis in Shanghai, China: a cross-sectional epidemiological study. Int Health. 2019:11(S1):S45-s54. https://doi.org/10.1093/inthealth/ihz053.

15. Xiao H, Zhang Y, Kong D, Li S, Yang N. Social capital and sleep quality in individuals who self-isolated for 14 days during the coronavirus disease 2019 (COVID-19) outbreak in January 2020 in China. Med Sci Monit. 2020;26: e923921. https://doi.org/10.12659/msm.923921.

16. Xinhua. China takes measures to ensure employment, work resumption: China Daily; 2020. https://global.chinadaily.com.cn/a/202004/202021/WS202 005e202009ea202039aa203105d202050a202003d202017c202036.html.

17. Zandifar A, Badrfam R. Iranian mental health during the COVID-19 epidemic. Asian J Psychiatr. 2020:51:101990. https://doi.org/10.1016/j.ajp.2020.101990.

18. Zhan, Z. (2020). Baidu Map migration big data real-timely shows the Spring Festival travel back situation (in Chinese). http://tech.gmw.cn/2020-2002/2 013/content_33552924.htm.

19. Zhou $X$, Bi B, Zheng L, Li Z, Yang H, Song H, Sun Y. The prevalence and risk factors for depression symptoms in a rural Chinese sample population. PLoS One. 2014:9(6):e99692. https://doi.org/10.1371/journal.pone.0099692.

\section{Publisher's Note}

Springer Nature remains neutral with regard to jurisdictional claims in published maps and institutional affiliations.

\section{Ready to submit your research? Choose BMC and benefit from:}

- fast, convenient online submission

- thorough peer review by experienced researchers in your field

- rapid publication on acceptance

- support for research data, including large and complex data types

- gold Open Access which fosters wider collaboration and increased citations

- maximum visibility for your research: over $100 \mathrm{M}$ website views per year

At BMC, research is always in progress.

Learn more biomedcentral.com/submission 